\title{
Destilasi Uap Minyak Atsiri dari Tanaman Serai Dapur (Cymbopogon citratus) dengan Pretreatment menggunakan Microwave
}

\section{Steam Distillation of Essential Oil from Lemongrass (Cymbopogon citratus) using Microwave Pretreatment}

\author{
Sri Wahyu Murni ${ }^{a^{*}}$, Tutik Muji Setyoningrum ${ }^{\mathrm{a}}$ and Gogot Haryono ${ }^{\mathrm{a}}$ \\ aProgram Studi Teknik Kimia Jurusan Teknik Kimia FTI UPN “Veteran” Yogyakarta \\ Jl. SWK 104 (Lingkar Utara) Condong Catur Yogyakarta 5528 Indonesia
}

\section{Artikel histori :}

Diterima 2 maret 2020 Diterima dalam revisi 5 Maret 2020 Diterima 27 Maret 2020 Online 31 Maret 2020

\begin{abstract}
ABSTRAK: Minyak atsiri dari serai dapur (Cymbopogon citratus) yang mengandung citral sangat potensial digunakan di industri, namun sampai sekarang masih terbatas penggunaannya. Proses isolasi minyak atsiri masih terkendala rendemen yang rendah, untuk menaikkan rendemen berbagai studi telah banyak dilakukan antara lain menggunakan microwave. Pada penelitian ini dilakukan isolasi minyak serai dapur dengan metode destilasi uap dengan pretreatment menggunakan microwave. Hasil penelitian menunjukkan pretreatment menggunakan microwave selama 2 menit berpengaruh menaikkan rendemen 1,4 kali dibandingkan tanpa pretreatment dan secara umum minyak atsiri yang dihasilkan memiliki sifat fisika yang mirip dengan tanpa pretreatment. Hasil analisis komposisi menggunakan GCMS menunjukkan minyak atsiri dengan pretreatment menggunakan microwave dan tanpa pretreatment mengandung geranial (E-citral atau citral-a), neral (Z-citral atau citral-b) dan mircena sebagai komponen utama yang teridentifikasi.
\end{abstract}

Kata kunci: serai dapur; minyak atsiri; destilasi uap; microwave; pretreatment

\begin{abstract}
Essential oils from lemongrass (Cymbopogon citratus) containing citral are very potential to be used in food and pharmacy industries. The process of isolating essential oils is still constrained by its low yield. In order to increase yield, in this research, isolation of essential oil by steam distillation method was carried out using microwave pretreatment. The results showed that pretreatment using microwave for 2 minutes had the effect of increasing yield up to 1.4 times compared to without pretreatment. The essential oil produced using microwave pretreatment had physical properties (colour, odor, density, and refractive index) similar to those without pretreatment. Composition analysis by GC-MS showed that essential oils extracted using microwave pretreatment and without pretreatment contain geranial (Ecitral or citral-a), neral (Z-citral or citral-b) and mircena as the main components.
\end{abstract}

Keywords: lemongrass; essential oil; steam distillation; microwave; pretreatment

\section{Pendahuluan}

Serai dapur atau Cymbopogon citratus (C. citratus) lebih sering digunakan untuk keperluan bumbu dapur, rempah, dan herbal tradisional khususnya di Asia. Selain itu serai jenis ini merupakan jenis yang paling umum di dunia dibandingkan dengan spesies lainnya. Namun penggunaannya masih terbatas dibandingkan kerabatnya yaitu serai wangi atau Cymbopogon nardus di dunia minyak atsiri. Padahal serai jenis ini memiliki potensi untuk digunakan sebagai minyak atsiri. Minyak atsiri dari serai dapur $C$. citratus digunakan sebagai flavor, parfume, industri farmasi dan industri kosmetik. $C$. citratus digunakan dalam pengobatan tradisional untuk pengobatan nervous, anti inflammatory, gangguan sakit perut, diuretic dan sedative. Hasil penelitian ekstrak $C$. citratus dapat digunakan sebagai anti oksidan, anti microbial dan antifungal activity. (Ajayi dkk., 2016; Negrelle dkk, 2007) $C$. citratus memiliki aroma lemon yang kuat karena mengandung senyawa aldehid yaitu citral, yang memiliki dua isomer geometri yaitu geranial (E-citral atau citral-a) dan neral (Z-citral atau citral-b) (Hanna dkk., 2012) Kedua isomer ini umumnya terdapat bersama-sama. Selain komponen utama teersebut di dalam minyak atsiri $C$. citratus juga terkandung komponen minor yaitu geranial, citronella dan jenis olefin yaitu mircena dan ocimene. Pengambilan minyak dari tanaman ini dapat menaikkan

*Corresponding Author:

Email: sriwahyumurni@gmail.com 
nilai jual dan memiliki potensi ekonomi untuk meningkatkan perekonomian petani serai di Indonesia.

Minyak serai dapat diisolasi dengan berbagai metode, baik konvensional maupun modern. Salah satu yang kini banyak dikembangkan yaitu dengan bantuan gelombang microwave yang digunakan pada saat ekstraksi (MAE, Microwave Assisted Extraction) maupun sebelum ekstraksi yaitu dengan perlakuan awal (pretreatment) menggunakan microwave. Beberapa studi menunjukkan bahwa metode ini dapat meningkatkan kuantitas zat yang diekstrak. Studi dan penelitian sejenis dengan bahan berbeda mengenai perlakuan awal menggunakan microwave telah dilakukan Azadmard-Damirchi dkk. (2011), menjelaskan keunggulan penggunaan perlakuan awal menggunakan microwave dibandingkan tanpa diberikan perlakuan pada ekstraksi minyak sayur. Kouba dkk. (2016) menjelaskan penggunaan teknologi baru seperti ultrasonic dan microwave untuk meningkatkan rendemen dan kualitas pada ekstraksi minyak dari tanaman berbiji yang mengandung minyak.

Energi dari microwave adalah alternatif yang baik untuk aplikasi termal karena produksi panasnya yang lebih efisien. Oven microwave menggunakan gelombang radio untuk menyampaikan energi dan mengkonversikannya ke panas dengan frekuensi sekitar $300 \mathrm{MHz}$ hingga $300 \mathrm{GHz}$. Gelombang dalam rentang frekuensi ini sangat banyak diserap oleh air dengan grup oksigen polar yang cukup. Pada teknologi pangan, penggunaan microwave telah sering digunakan dengan peningkatan keberhasilannya pada ekstraksi minyak, pasteurisasi, sterilisasi, memasak, mengeringkan, hingga mencairkan es dari berbagai produk makanan. Kemampuan penetrasi microwave tergantung dari sifat elektrik dan fisik bahan, komposisi kimia, pola pemanasan, inaktivasi mikroba, dan kontrol kualitas. (Azadmard-Damirchi, dkk., 2011) Pemberian gelombang micro akan memecah membran sel pada tanaman dan membentuk pori-pori pada sel tanaman sehingga minyak dapat berpindah melalui dinding sel yang bersifat permeable. Hal ini mengakibatkan rendemen ekstraksi yang lebih tinggi dan terjadi kenaikan koefisien transfer massa. Menurut Surjani Wonorahardjo (2013), ekstraksi dengan gelombang mikro, gelombang mikro dengan energi rotasi molekul tertentu akan membantu ekstraksi bahan kimia dari matriks yang sulit, seperti jaringan tumbuhan yang tidak lunak. Seperti halnya ekstraksi dengan ultrasonikasi, gelombang mikro dipilih karena dapat membantu proses ekstraksi. Azadmard-Damirchi, dkk. (2011), menyatakan bahwa pretreatment dengan microwave dapat digunakan sebagai alternatif dari teknik ekstraksi minyak konvensional. Pretreatment yang dilakukan dengan cara memanaskan bahan baku dalam waktu tertentu dengan microwave memiliki efek positif terhadap jumlah minyak dapat terambil. Dengan pemanasan ini, microwave masuk ke dalam bahan, kemudian berpropagasi berubah menjadi panas. Sinar micro dapat memecah membrane sel biji dan menyebabkan pori pada struktur biji, hasilnya pada proses ekstraksi dengan pelarut, pelarut dapat masuk dan melarutkan dengan lebih baik. Rendemen minyak yang diekstrak dengan $M A E$ lebih tinggi dibanding dengan yang diperoleh dari ekstraksi minyak konvensional pada kondisi yang sama. Kelebihan dari pretreatment dengan microwave adalah waktu ekstraksi dan biaya konsumsi energi yang lebih sedikit jika dibandingkan dengan metode konvensional. Pada hasil yang diperoleh, minyak hasil ekstraksi dengan microwave juga memiliki sifat yang mirip dengan minyak yang diekstraksi secara konvensional.

Koubaa, dkk (2016) juga menyatakan bahwa pretreatment dengan microwave dan MAE merepresentasikan alternatif yang baik dari ekstraksi minyak secara konvensional. Penambahan gelombang microwave pada ekstraksi mengarah pada kenaikan rendemen dan/atau nilai nutrisi dari minyak biji. Selain itu dinyatakan pula terjadinya penurunan waktu ekstraksi dan biaya konsumsi energi. Sebagian besar studi menyatakan kemiripan atau kenaikan kualitas minyak pada bahan dnegan pemberian microwave dibandingkan yang tidak diberi perlakuan. Selain itu pemberian microwave menaikkan nutrisi dan kandungan seperti phytosterols dan tocopherols, canolol, dan senyawa fenol yang menaikkan kestabilan oksidatif dari minyak dan menaikkan waktu simpan. Desai dan Parikh (2015), dalam penelitiannya menyebutkan bahwa minyak serai yang diekstraksi menggunakan MAE, memiliki kandungan yang kaya akan senyawa teroksigenasi terutama sitral (80-89\%), memiliki kenaikan aktivitas antimikroba dan antioksidan dibandingkan yang diekstrak dengan hidrodistilasi. Selain itu waktu ekstraksi yang diperlukan dengan MAE lebih sedikit dibandingkan dengan metode hidrodistilasi.

Mekanisme ekstraksi dengan bantuan gelombang mikro meliputi tiga tahapan, yaitu: 1). Pemisahan solut (bahan aktif) dari sisi aktif pada matriks bagian tanaman sebagai akibat peningkatan suhu dan tekanan, 2). Difusi pelarut melalui matriks tanaman dan 3). Pelepasan solut (bahan aktif) dari matriks bagian tanaman menuju pelarut. (Andri Cahyo Kumoro, 2015) Beberapa kelebihan metode ekstraksi berbantuan gelombang mikro diantaranya adalah: laju pemanasan lebih cepat, gradien suhu rendah, ukuran peralatan lebih kecildan rendemen ekstraksi yang tinggi. (Andri Cahyo Kumoro, 2015)

Pada penelitian ini akan dipelajari pengaruh pretreatment menggunakan microwave pada pengambilan minyak atsiri dari serai dapur (C. citratus) dengan metode destilasi uap, terhadap sifat fisik, rendemen minyak atsiri dan komposisinya.

\section{Metode Penelitian}

Penelitian ini dilakukan melalui tahapan persiapan bahan baku, percobaan utama, serta analisis hasil. Persiapan bahan baku dilakukan pengeringan dan pengecilan ukuran bahan. Proses destilasi uap dilakukan tanpa dan dengan pretreatment menggunakan microwave.

\subsection{Bahan}

Bahan yang digunakan dalam penelitian ini adalah serai dapur yang diperoleh dari pasar tradisional Stan, Maguwoharjo, Depok Sleman Yogyakarta.

\subsection{Alat}

Alat yang digunakan dalam penelitian ini adalah microwave Aqua AEM-S2612S dengan frekuensi 2450 
$\mathrm{MHz}$, tegangan $220 \mathrm{~V}$, konsumsi daya $800 \mathrm{~W}$ dan alat destilasi uap disajikan pada Gambar 1 .

\subsection{Cara Kerja}

\subsubsection{Persiapan Bahan Baku}

Persiapan bahan baku meliputi pencucian, pengeringan dan pengecilan ukuran. Serai dibersihkan dari pengotor dan dikeringkan dengan cara dijemur di tempat teduh hingga kering. Serai yang sudah dikeringkan, dipotong dengan ukuran sekitar $0,5-1 \mathrm{~cm}$.

\subsubsection{Percobaan Utama}

Bahan baku serai sebanyak 1000 gram dipanaskan dengan microwave pada frekuensi $2450 \mathrm{MHz}$ dengan output $800 \mathrm{~W}$, selama 2 menit; kemudian dimasukkan ke dalam alat destilasi uap (Gambar 1.), waktu destilasi dimulai sejak tetesan pertama kondensat terbentuk. Kondensat hasil distilasi dikumpulkan dan dipisahkan minyak dan airnya, selanjutnya dikeringkan. Minyak atsiri yang dihasilkan dianalisis. Percobaan juga dilakukan dengan bahan baku yang tidak diberi pretreatment menggunakan microwave.

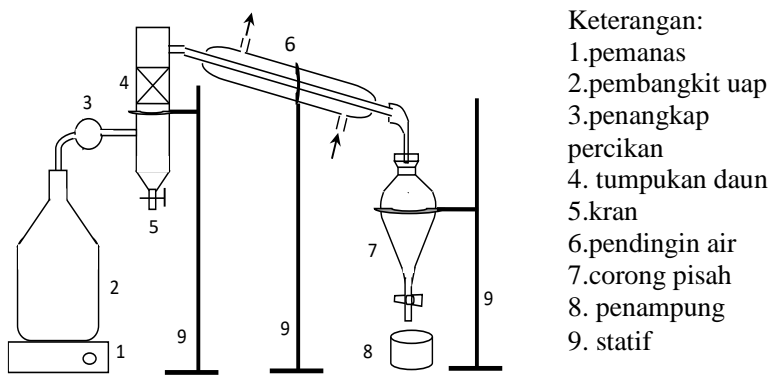

Gambar 1. Rangkaian Alat Destilasi Uap

\subsection{Analisis Hasil}

Minyak atsiri yang dihasilkan setelah dipisahkan, diamati sifat fisiknya meliputi kenampakan (warna), bau dan densitas. Komposisi dianalisis menggunakan alat Gas Chromatography-Mass Spectroscopy (GC-MS) serta ditentukan rendemennya dengan persamaan:

rendemen minyak atsiri $=\frac{\text { [umlah minyak atsiri (gr) yang didapat }}{\text { [umlah bahan baku (gr)yang digunakan }}$

Gas Chromatography-Mass Spectroscopy (GC-MS)

Analisis GC-MS menggunakan tipe GC-MS-QP2010S SHIMADZU, Kolom Rtx 5MS, panjang 30 m, ID 0,25 $\mathrm{mm}$, tebal film $0,25 \mu \mathrm{m}$, gas pembawa helium, pengion $\mathrm{El}$ $70 \mathrm{Ev}$, suhu oven $50-240^{\circ} \mathrm{C}$. Persentase senyawa dihitung dengan metode normalisasi luas, tanpa memperhitungkan respon faktor

\section{Hasil dan Pembahasan}

Minyak atsiri dari tanaman serai dapur yang dihasilkan dengan proses destilasi uap berbau khas lemon dan berwarna kuning pucat, Gambar 1. menunjukkan bahwa minyak atsiri yang diperoleh dengan perlakuan awal menggunakan microwave diperoleh warna minyak yang lebih terang. Analisis sifat fisika dilakukan untuk mengetahui karakter minyak serai dapur hasil penelitian dibandingkan dengan kualitas minyak sereh berdasarkan SNI No. 06-3953-1995; hasil analisis disajikan pada Tabel 1. Rendemen minyak atsiri yang diperoleh dengan perlakuan awal menggunakan microwave 2 menit menunjukkan peningkatan 1,4 kali lebih besar dibandingkan tanpa perlakuan awal. Azadmard-Damirchi, dkk. (2011) menyatakan microwave akan berpenetrasi ke dalam jaringan sel tanaman dan memecah membran poripori tanaman sehingga minyak lebih mudah berpindah melalui dinding sel yang permeabel. Kemampuan penetrasi bergantung pada kekuatan microwave dan sifat fisik bahan.

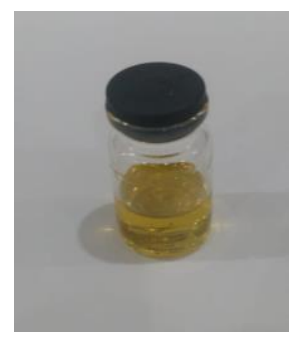

(a)

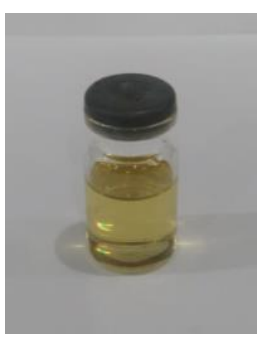

(b)
Gambar 2. Minyak serai dapur hasil destilasi uap: (a) tanpa pretreatment awal, (b) dengan pretreatment microwave 2 menit.

Tabel 1. Hasil uji sifat fisik dan rendemen minyak sereh dapur

\begin{tabular}{|c|c|c|c|}
\hline \multirow{2}{*}{$\begin{array}{l}\text { Parameter } \\
\text { analisis }\end{array}$} & \multicolumn{2}{|c|}{ Hasil analisis } & \multirow[b]{2}{*}{$\begin{array}{c}\text { SNI minyak } \\
\text { sereh No. 06- } \\
\text { 3953-1995 } \\
\text { (Andropogon } \\
\text { nardus de } \\
\text { Joung) }\end{array}$} \\
\hline & $\begin{array}{c}\text { tanpa } \\
\text { pretreatment }\end{array}$ & $\begin{array}{c}\text { dengan } \\
\text { pretreatment } \\
\text { microwave }\end{array}$ & \\
\hline Warna & Kuning pucat & Kuning pucat & $\begin{array}{c}\text { Tidak } \\
\text { berwarna- } \\
\text { kuning }\end{array}$ \\
\hline $\mathrm{Bau}$ & Lemon & Lemon & Lemon \\
\hline $\begin{array}{l}\text { Berat Jenis } \\
(\mathrm{g} / \mathrm{ml})\end{array}$ & 0,8975 & 0,8976 & $0,8975-0,893$ \\
\hline Indeks bias & 1,4595 & 1,4597 & $1,466-1,475$ \\
\hline $\begin{array}{l}\text { Rendemen } \\
(\%)\end{array}$ & 0,93 & 1,23 & - \\
\hline
\end{tabular}

\section{Analisis Komposisi Minyak Sereh}

Komposisi minyak atsiri dianalisis menggunakan GCMS menunjukkan 12 komponen dalam minyak atsiri hasil destilasi uap tanpa pretreatment menggunakan microwave dan 8 komponen dalam minyak atsiri hasil destilasi uap dengan pretreatment menggunakan microwave selama 2 menit. Senyawa kimia penyusun minyak atsiri disajikan pada Gambar 3 dan 4, serta Tabel 2. Komponen diurutkan berdasar waktu retensi pada kolom Rtx 5MS. Komponen utama minyak serai yang diperoleh dengan destilasi uap tanpa pretreatment dan dengan pretreatment menggunakan 
microwave 2 menit berturut-turut adalah geranial atau citral-a $(63,88 \%$ dan $60,49 \%)$, neral atau citral-b $(32,1 \%$ dan $33,49 \%)$, myrcena $(0,89 \%$ dan $2,72 \%)$, undecyne $(1,12 \%$ dan $1,5 \%)$. Kualitas minyak serai umumnya.

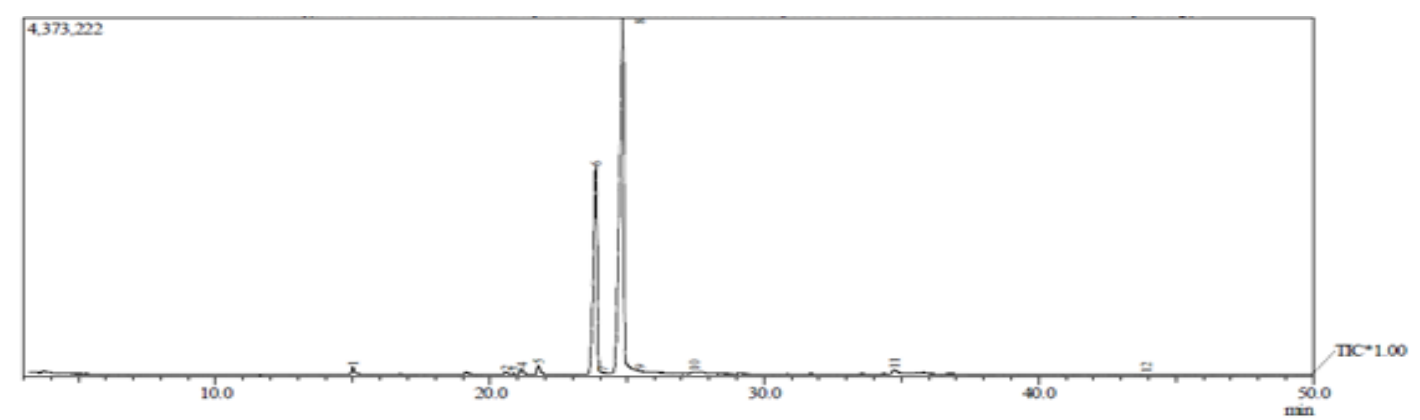

Gambar 3. Kromatogram minyak atsiri serai dapur Cymbogon citratus hasil destilasi uap tanpa pretreatment menggunakan microwave

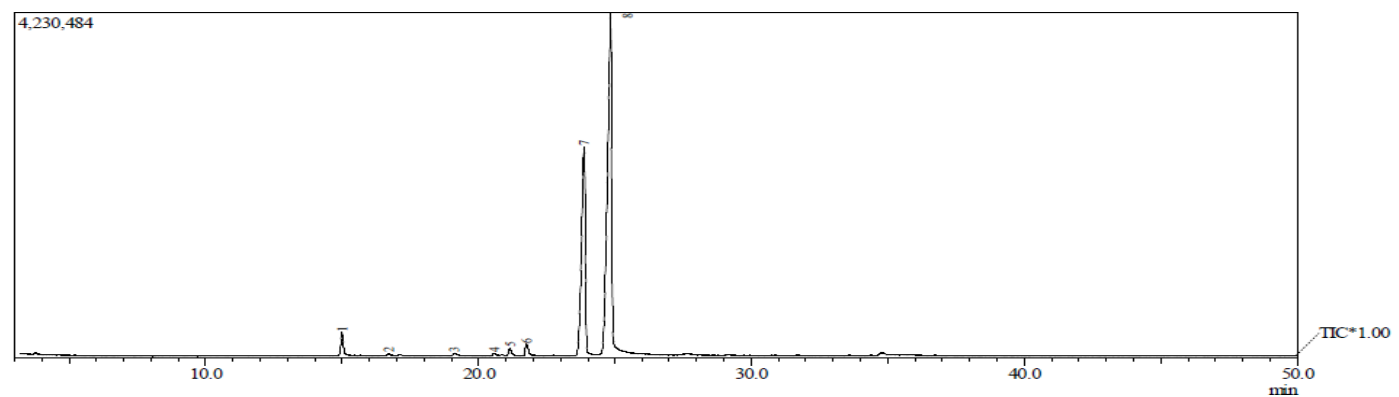

Gambar 4. Kromatogram minyak atsiri serai dapur Cymbogon citratus hasil destilasi uap dengan pretreatment menggunakan microwave 2 menit

Tabel 2. Komposisi minyak sereh hasil destilasi uap tanpa pretreatment dan dengan pretreatment menggunakan microwave

\begin{tabular}{|c|c|c|c|c|c|c|}
\hline \multirow[t]{2}{*}{ Senyawa } & \multirow[t]{2}{*}{$\begin{array}{l}\text { Rumus } \\
\text { Kimia }\end{array}$} & \multirow[t]{2}{*}{$\mathrm{BM}^{*}$} & \multicolumn{2}{|c|}{$\begin{array}{c}\text { minyak } \\
\text { tanpa } \\
\text { pretreatment }\end{array}$} & \multicolumn{2}{|c|}{$\begin{array}{c}\text { minyak dengan } \\
\text { pretreatment } \\
\text { microwave }\end{array}$} \\
\hline & & & RT * & $\%$ & $\mathrm{RT}^{*}$ & $\%$ \\
\hline $\begin{array}{l}\text { Myrcene } \\
\text { (7-metil-3-metilena- } \\
\text { 1,6-oktadiena) }\end{array}$ & $\mathrm{C}_{10} \mathrm{H}_{16}$ & 136 & 15 & 0,89 & 14,995 & 2,72 \\
\hline $\begin{array}{l}\text { Ocimene } \\
\text { (2,6-dimetil-1,3,7- } \\
\text { oktatriena) }\end{array}$ & $\mathrm{C}_{10} \mathrm{H}_{16}$ & 136 & - & - & 16,721 & 0,22 \\
\hline $\begin{array}{l}\text { Linalool } \\
(3,7 \text {-dimetil-1,6- } \\
\text { oktadien-3-ol ) }\end{array}$ & $\mathrm{C}_{10} \mathrm{H}_{18} \mathrm{O}$ & 154 & - & - & 19,108 & 0,36 \\
\hline 2,6-nonadienal & $\mathrm{C}_{9} \mathrm{H}_{16}$ & 138 & 20,59 & 0,25 & 20,562 & 0,36 \\
\hline $\begin{array}{l}\text { Citronella } \\
\text { (3,7-dimetil-6- } \\
\text { oktenal) }\end{array}$ & $\mathrm{C}_{10} \mathrm{H}_{18} \mathrm{O}$ & 154 & 20,850 & 0,08 & - & - \\
\hline $\begin{array}{l}\text { 3-Undecyne } \\
(\mathrm{C} 11 \mathrm{H} 20)\end{array}$ & $\mathrm{C}_{11} \mathrm{H}_{20}$ & 152 & 21,155 & 0,69 & 21,156 & 0,86 \\
\hline limonene 1,2 - oksida & $\mathrm{C}_{10} \mathrm{H}_{16} \mathrm{O}$ & 152 & 21,767 & 1,12 & 21,765 & 1,5 \\
\hline $\begin{array}{l}\text { neral/citral b } \\
\text { ( cis-3,7-dimetil-2,6- } \\
\text { oktadienal) }\end{array}$ & $\mathrm{C}_{10} \mathrm{H}_{16} \mathrm{O}$ & 152 & 23,859 & $\begin{array}{c}32,1 \\
0\end{array}$ & 23,869 & 33,49 \\
\hline 1,2,4-trimetilbenzena & $\mathrm{C}_{9} \mathrm{H}_{12}$ & 120 & 24,108 & 0,05 & - & - \\
\hline $\begin{array}{l}\text { geranial/citral a } \\
\text { ( trans-3,7-dimetil- } \\
\text { 2,6-oktadienal) }\end{array}$ & $\mathrm{C}_{10} \mathrm{H}_{16} \mathrm{O}$ & 152 & 24,842 & $\begin{array}{c}63,8 \\
8\end{array}$ & 24,839 & 60,49 \\
\hline $\begin{array}{l}\text { O-methyl-N-butyl } \\
\text { pivalimidate }\end{array}$ & $\begin{array}{c}\mathrm{C}_{10} \mathrm{H}_{21} \mathrm{~N} \\
\mathrm{O}\end{array}$ & 171 & 25,458 & 0,02 & - & - \\
\hline eugenol & $\mathrm{C}_{10} \mathrm{H}_{12} \mathrm{O}_{2}$ & 164 & 27,450 & 0,13 & - & - \\
\hline globulol & $\mathrm{C}_{15} \mathrm{H}_{26} \mathrm{O}$ & 262 & 34,758 & 0,73 & - & - \\
\hline $\begin{array}{l}7- \\
\text { hidroksinorlumiflavin }\end{array}$ & $\begin{array}{l}\mathrm{C}_{12} \mathrm{H}_{10} \mathrm{~N}_{4} \\
\mathrm{O}_{3}\end{array}$ & 258 & 43,925 & 0,03 & - & - \\
\hline
\end{tabular}


ditentukan dari kandungan citral. Hasil menunjukkan bahwa penggunaan microwave menaikkan kandungan mircena, menaikkan kadar neral dan menurunkan geranial. Secara umum minyak atsiri yang diperoleh dengan perlakuan awal menggunakan microwave memiliki sifat yang mirip dengan tanpa pretreatment

\section{Kesimpulan}

Minyak serai dapur (C. citratus) hasil destilasi uap tanpa dan dengan pretreatment menggunakan microwave memenuhi syarat SNI No. 06-3953-1995 tentang persyaratan mutu minyak serai. Rendemen destilasi uap tanpa dan dengan pretreatment menggunakan microwave berturut-turut adalah 0,93 dan 1,23. Kandungan senyawa citral betutut-turut $95,98 \%$ (citral a-65,88\% dan citral-b $32,1 \%$ ) dan $93,98 \%$ (citral-a 60,49\% dan citral-b 33,4\%). Pretreatment dengan microwave menaikan rendemen, menaikkan kandungan mircena dan geranial dan menurunkan kadar neral. Secara umum minyak atsiri yang dihasilkan dengan pretreatment microwave 2 menit memiliki sifat yang mirip dengan tanpa pretreatment menggunakan microwave

\section{Ucapan Terima kasih}

Ucapan terima kasih disampaikan kepada LPPM UPN "Veteran" Yogyakarta yang telah memberikan dana penelitian melalui Skim Penelitian Dasar Batch I tahun 2019 sehingga penelitian ini dapat terlaksana.

\section{Daftar Pustaka}

Noh, D.O., Kim, S.H. \& Gilliland, S.E., 1997, Incorporation of cholesterol into the cellular membrane of Lactobacillu acidphilus, Jurnal Exergy, Vol.2 No.1, Juni: 07-13.

Ajayi, E. O., A. P. Sadimenko, A. J. Afolayan, 2016, GCMS evaluation of Cymbopogon citratus (DC) stapf oil obtained using modified hidrodistillation and microwave extraction methods, Food Chemistry, Vol. 209. Pg 262-266.

Ajayi, E. O., A. P. Sadimenko, A. J. Afolayan, 2016, Data showing chemical compositions of essential oil of leaves of Cymbopogon citratus obtained by varying $\mathrm{pH}$ ohf the extraction medium, Data in Brief, . Vol. 8. Pg 599-604

Andri Cahyo Kumoro, 2015, Teknologi Ekstraksi Senyawa Bahan Aktif dari Tanaman Obat, Plantaxia, cetakan pertama, Yogyakarta

Azadmard-Damirchi, S., Fatemeh Habibi-Nodeh, Javad Hesari, Mabbob Nemati, Behram Fathi Achachlouei, 2010, Effect of pretreatment with microwaves on oxidative stability and nutraceutical of oil from rapeseed, Food Chemistry, Vol. Pg. 1211-1215

Azadmard-Damirchi, S., K. Alirezalu, dan B. Fathi Achachlouei, 2011, Microwave Pretreatment of Seeds to Extract High Quality Vegetable Oil. International Journal of Nutrition and Food Engineering 5. No. 9

Carlson, L.H.C, C. B. S. Machad, L. K. Pereira, and A. Bolzan, 2001, Extraction of lemongrass essential oil with dense carbon dioxide, Journal of Supercritical Fluids. Vol. 21. pg. 33-39.

Desai, Meghal A., dan Jigisha Parikh. 2015. Extraction of oil from Leaves of Lemongrass Using Microwave Radiation: Optimization, Comparative, Kinetic, and Biological Studies, ACS Sustainable Chemistry \& Engineering. Vol. 3. Pg. 421-431.

Hanaa, A.R Mohamed, Y. I. Salam, A. S. El-Leithy, Safaa E. Aly. 2012. Lemongrass (Cymbopogon Citratus) essential oil as effected by drying methods. Annals of Agricultural Science. Volume 57. No 2. Pg. 113116.

International Organization for Standardization. ISO 3217:1974, Oil of Lemongrass (Cymbopogon citratus). Diakses dari https://www.iso.org/standard/8421.html?browse=tc pada 30 Januari 2018

Koubaa, Mohamed., Houcine Mhemdi, Francisco J. Barba, Shahin Roohinejad, Ralf Greiner, Eugene Vorobiev. 2016. Oilseed treatment by ultrasonic and microwaves to improve oil rendemen and quality: An Overview. Food Research International. Volume 85, pg. 59-66.

Negrelle, R.R.B., Gomes, E.C, 2007, Cymbopogon citratus (DC) Stapf: chemical composition and biological activities, Rev. Bras. PI Med,., Botucatu, Vol 9, No. $1, \operatorname{Pg} 8-92$

Ranitha M, Abdurahman H. Nour, Ziad A. Sulaiman, Azhari H. Nour dan Thana Raj S., 2014, A Comparative Study of Lemongrass (Cymbogon citratus) Essential Oil Extracted by MicrowaveAssisted Hydrodistillation (MAHD) and Conventional Hydrodistillation (HD) Method, International Journal of Chemical Engineering and Application, Vol. 5, No. 2

Sastrohamidjojo, Hardjono, 2004, Kimia Minyak Atsiri, Yogyakarta: Gadjah Mada University Press. Hal 10.

Tim Redaksi Trubus, 2009, Herbal Indonesia Berkhasiat, Bukti Ilmiah dan Cara Racik. Depok: PT Trubus Swadaya

Wonorahardjo, Surjani, 2013, Metode-Metode Pemisahan Kimia, Sebuah Pengantar. Jakarta: Akademia Permata 